\title{
Filhos afastados de suas famílias: ações e concepções dos profissionais
}

Children taken away from their families: professional actions and conceptions

Hijos separados de sus familias: acciones y concepciones de los profesionales.

\section{Mara Fernanda Córdova}

Universidade Comunitária da Região de Chapecó, Chapecó, SC, Brasil.

Irme Salete Bonamigo

Universidade Comunitária da Região de Chapecó, Chapecó, SC, Brasil.

\section{Resumo}

Este artigo tem como objetivo analisar as ações e concepções de profissionais ligados ao Sistema de Garantia de Direitos da Criança e do Adolescente sobre as famílias que têm os filhos afastados de sua convivência. Trata-se de relato de pesquisa realizada em uma cidade do oeste da Santa Catarina, por meio das técnicas de entrevista, de grupo focal e da análise de documentos produzidos pelos profissionais. Fundamenta-se em noções de Michel Foucault. Os resultados indicam que o afastamento de crianças e adolescentes de suas famílias tem se dado com base em um discurso de culpabilização e criminalização da família, considerada incapaz de bem cuidar de seus filhos, por condições majoritariamente associadas à situação de pobreza em que vivem. Os profissionais compreendem que essas famílias fizeram escolhas por modos de vida que não condizem com o esperado socialmente para a maternidade/paternidade.

Palavras-chave: Políticas Sociais, Direitos da Criança e do Adolescente, Serviços de Acolhimento.

\begin{abstract}
This work aims to analyze actions and conceptions of professionals linked to the System of Assurance of Rights of Children and Adolescents concerning families whose children were taken away. This is about a research report conducted in a western city in the state of Santa Catarina through techniques of interview, focus group and analysis of documents produced by the professionals involved. It is based on Michel Foucault's ideas. Results show that children and adolescents removal from their families has happened based on a discourse of culpability and criminalization of the family who is considered incapable of taking care of their children mainly due to the poverty they live in. These professionals understand those families ended up making choices which are not in accordance to what is socially expected for parenthood.
\end{abstract}


Key-Words: Social Policy, Children and adolescent rights, Children and adolescent admission services.

\section{Resumen}

Este artículo tiene como objetivo analizar las acciones y concepciones de los profesionales del Sistema de Garantía de Derechos del Niño y del Adolescente sobre las familias que tienen los hijos separados de su convivencia. Se trata del relato de la investigación realizada en una ciudad del oeste da Santa Catarina, por medio de las técnicas de entrevista, grupo focal y análisis de documentos producidos por los profesionales. Se fundamenta en nociones de Michel Foucault. Los resultados indican que la separación de niños y adolescentes de sus familias ha sido realizada con base en un discurso de culpa y criminalización de la familia, considerada incapaz de cuidar bien a sus hijos, por condiciones mayoritariamente asociadas a la situación de pobreza en la que viven. Los profesionales comprenden que esas familias han escogido modos de vida que no condicen con lo esperado socialmente para la maternidad/paternidad.

Palabras-clave: Políticas sociales, Derechos del niño y del adolescente, Servicios de acogimiento

\section{Introdução}

Este artigo discute ações e concepções de profissionais ligados ao Sistema de Garantia de Direitos da Criança e do Adolescente (SGDCA) relativas ao tema do afastamento de crianças e adolescentes de suas famílias, mediante aplicação de medida prevista no Estatuto da Criança e do Adolescente (ECA), que compete exclusivamente ao juizado e, em casos emergenciais, ao Conselho Tutelar ou à própria instituição de acolhimento. Intentamos desvelar concepções que atravessam as ações dos profissionais nesse universo do tema pesquisado. Para Foucault (2000, p. 8), “(...) as práticas sociais podem chegar a engendrar domínios de saber que não somente fazem aparecer novos objetos, novos conceitos, novas técnicas, mas também fazem nascer formas totalmente novas de sujeitos e de sujeitos de conhecimento."

Nessa perspectiva, acreditamos que as práticas discursivas e não discursivas contribuem com elementos que nos auxiliam a identificar saberes contemporâneos que são tecidos nos cruzamentos entre leis, famílias, especialistas e normas sociais. Nessa inter- 
relação, formam-se verdades, definem-se modos de viver e determinam-se punições para os que não se conformam a tais funcionamentos. Foucault (2000, p. 11) afirma:

(...) parece-me que existem, na sociedade, ou pelo menos, em nossas sociedades, vários outros lugares onde a verdade se forma, onde um certo número de regras de jogo são definidas - regras de jogo a partir das quais vemos nascer certas formas de subjetividade, certos domínios de objeto, certos tipos de saber - e por conseguinte podemos, a partir daí, fazer uma história externa, exterior, da verdade.

Os discursos dos profissionais são ricos em ditar regras, anunciar desvios, formar e reafirmar verdades "universais" que se engendram em um jogo discursivo. Assim, consideramos importante abranger, como estratégia teórico-metodológica de pesquisa, a rede discursiva ao qual tais discursos estão vinculados: políticas públicas, processos judiciais, relatórios, pareceres etc. É importante ressaltar que os discursos não foram analisados como unidades fechadas ou homogêneas, mas como multiplicidades de enunciados, em um campo complexo de discursos (Foucault, 1995, p. 26).

A pesquisa foi realizada no ano de 2011, em uma cidade do oeste de Santa Catarina. As técnicas de pesquisa utilizadas foram as seguintes: grupo focal, entrevista, observação e análise de documentos. Participaram das entrevistas e do grupo focal 12 profissionais ligados ao SGDCA (Juiz, Assistente Social vinculada ao Tribunal de Justiça, Assistente Social e Pedagogo dos Serviços de Acolhimento, Membro do Conselho Municipal dos Direitos da Criança e do Adolescente, Psicóloga da Delegacia Especializada, Membro do Conselho Tutelar, Psicólogos e Assistentes Sociais de serviços de Assistência Social). A pesquisa documental foi realizada por meio de acesso e análise dos registros de entrada e saída, pastas individuais, processos judiciais e registros de atendimento de crianças e adolescentes, entre os anos de 2007 e 2010, do Serviço de Acolhimento, do Centro de Referência de Assistência Social (CRAS), do Centro de Referência Especializado de Assistência Social (CREAS), do Conselho Tutelar e do Judiciário. A opção por esses serviços se deu em função de que eles estão mais diretamente ligados à situação da medida de acolhimento.

O interesse pela realização da pesquisa foi provocado pela trajetória profissional da primeira autora, que atuou como psicóloga nos Serviços de Acolhimento e, posteriormente, no Poder Judiciário catarinense. A vivência e 
observação em seu cotidiano profissional evocaram reflexões e questionamentos acerca das formas como se efetivavam o afastamento de crianças e adolescentes de suas famílias. A análise das implicações da pesquisadora em relação a sua prática também serviu como fonte de dados da pesquisa.

\section{Redes Discursivas Sobre Famílias que}

Têm os Filhos Afastados de sua

\section{Convivência}

Os documentos analisados sobre o afastamento de crianças e adolescentes de suas famílias indicam que os principais motivos que levam à aplicação dessa medida são a negligência, o uso de álcool e outras drogas pelos pais ou responsáveis e o abandono. A análise conjunta dos documentos e entrevistas demonstra que, muito além da categorização apontada anteriormente sobre os principais motivos do encaminhamento de crianças e adolescentes aos Serviços de Acolhimento, as famílias são percebidas pelos profissionais imersas em diversas problemáticas e condições de vida associadas à situação de pobreza, a partir da qual se constroem cenários de violação de direitos. O olhar descontextualizado para a prática da negligência, o abandono ou o envolvimento com álcool e drogas

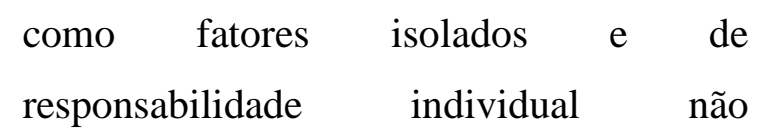
corresponde à realidade dessas questões, como poderemos compreender neste artigo.

Um dos aspectos identificados pelos profissionais no que se refere às famílias que têm os filhos afastados de sua convivência é o da percepção de que estas não contam com o suporte social adequado para garantir os direitos de seus filhos. Para alguns profissionais, “(...) as famílias em si estão sendo negligenciadas, estão sendo abandonadas e acabam abandonando seus filhos, acabam maltratando seus filhos por conta da condição que elas estão.” (Trecho de entrevista com profissional, 2011). Embora a pobreza não seja motivo para a aplicação da medida de afastamento, são as famílias pobres que têm sido alvo dessas ações, especialmente em decorrência da falta ou insuficiência de políticas públicas eficazes. Para Nascimento, Cunha e Vicente (2008), as práticas do período do código de menores (1979) em que indiscriminadamente se institucionalizavam crianças e adolescentes pela condição de pobreza familiar não deixaram de existir, tão somente se atualizaram.

Já não é mais justificável legalmente retirar o poder familiar por pobreza, mas é 
possível fazê-lo alegando-se a negligência ou os maus-tratos. Como o processo de criminalização da pobreza faz associações imediatas entre os pobres e os maustratos/negligência para com seus filhos - é possível burlar o ECA, destituindo o poder familiar dos mais pobres. (Nascimento, Cunha e Vicente, 2008, p. 12).

Para os profissionais, a insuficiência ou a ineficiência de políticas públicas está na origem de toda a problemática:

[Os] motivos da institucionalização de criança ou de um adolescente têm a ver diretamente com a carência de políticas públicas de atendimentos às famílias, às crianças e aos adolescentes. De certa forma o Estado ele é um ator dos mais importantes, mas ele é um ator que não entra em cena. (...) Se a gente for procurar crianças e adolescentes da classe média e da classe com maior poder aquisitivo a gente não vai encontrar crianças $\mathrm{e}$ adolescentes institucionalizados. $\mathrm{O}$ que será que está permeando este quadro, o que está sendo camuflado? (...) de alguma maneira isso vem se repetindo historicamente no nosso país e o recado que é repassado à sociedade é outro: o problema está na criança, está na família, no adolescente, mas não está no poder público. (Trecho de entrevista com profissional, 2011).

Os profissionais compreendem que as políticas públicas não têm contribuído para a garantia do direito à convivência familiar e comunitária e que, em muitas situações, o afastamento tem ocorrido devido ao pouco resultado que as políticas sociais alcançam quando se trata de auxiliar a família a superar suas dificuldades. $\mathrm{Na}$ contramão dessa constatação, observamos que políticas, programas e ações governamentais evocam a diretriz do trabalho visando ao fortalecimento e à manutenção de vínculos familiares, à prevenção do rompimento e à garantia da primazia da permanência de crianças e adolescentes com suas famílias. A família tem sido enaltecida e apresentada como o melhor lugar para as crianças crescerem; em consequência, a instituição familiar tem centralidade e deve ser o foco das atenções das ações públicas. Essa nova posição em que a família se encontra, ao mesmo tempo que a privilegia, também a culpabiliza por não dar conta da tarefa de cuidar dos filhos.

Para os profissionais, a falha está nas políticas de prevenção - ações em que a rede de serviços não teria avançado no mesmo ritmo em que os programas são elaborados e o trabalho preventivo eficaz poderia representar a permanência da criança junto a sua família. As famílias, consideradas sem preparo para cuidar bem das crianças e dos adolescentes e postas em cheque diante de novas legislações e 
normas sociais, estariam transferindo a responsabilidade de educar para outras instituições, tais como escola, serviços sociais, conselheiros.

Os serviços de assistência social estão organizados em níveis de complexidade, e o fluxo de atendimento dentro das instituições é seguido por muitas famílias. Essa rede funciona não de forma a oferecer suporte para a família, mas engendrando-se para culpabilizá-la e para encontrar argumentos que justifiquem o afastamento das crianças e a destituição do poder familiar. Com base no texto de Foucault sobre as organizações disciplinares, a seguir, podemos buscar suporte para compreender como isso se dá.

É um conjunto extremamente complexo sobre o qual somos obrigados a perguntar como ele pode ser tão sutil em sua distribuição, em seus mecanismos, seus controles recíprocos, seus ajustamentos, se não há quem tenha pensado o conjunto. É um mosaico muito complicado. Em certos períodos, aparecem agentes de ligação... Tomemos o exemplo da filantropia no início do século XIX: pessoas que vêm se ocupar da vida dos outros, de sua saúde, da alimentação, da moradia... Mais tarde, desta função confusa saíram personagens, instituições, saberes... uma higiene pública, inspetores, assistentes sociais, psicólogos. E hoje assistimos a uma proliferação de categorias de trabalhadores sociais. (Foucault, 2000, p. 151).

Historicamente

podemos acompanhar como os profissionais foram conclamados a intervir nas famílias, na busca de corrigir comportamentos que pudessem significar risco para as crianças e os adolescentes; e isso ocorreu por meio de uma aliança formada entre as instâncias jurídicas e um corpo técnico ligado ao social, que alcançou o poder para adentrar no íntimo das famílias e classificar, dirigir e decidir sobre a vida dos seus membros.

Não obstante toda essa estrutura de serviços, o que se observa é que “(...) as famílias não estão sendo atendidas suficientemente. Eu penso que as políticas públicas elas são pontuais, paliativas, periféricas... O que nós temos hoje que realmente venha empoderar a família?" (Trecho de entrevista com profissional, 2011).

Temos dois fatores bastante entrelaçados e que dificultam a garantia do direito à convivência familiar e comunitária: a condição de pobreza das famílias e a ineficácia das políticas públicas. Muitas famílias são as vítimas primeiras da negligência, do abandono. Estão inscritas em um processo de exclusão social que as empurra para a marginalidade e para todo um contexto de violação de direitos, aspectos que não estão restritos à criança e ao adolescente, mas se 
estendem a todo o grupo familiar. Nessa condição, é possível entender a dificuldade em atender ao padrão social de cuidado e atenção às crianças e aos adolescentes, especialmente quando as políticas sociais não oferecem o apoio para preencher as lacunas do processo de exclusão social. Os fenômenos do abandono, da negligência e outras violências estão permeados, muitas vezes, pela situação estrutural da vida das pessoas. Sobre a família pobre está o olhar observador dos profissionais que intervêm e formam sobre ela um campo de controle e vigilância. $\mathrm{Na}$ introdução do livro Microfísica do Poder, de Foucault (2000), Roberto Machado faz referência aos instrumentos disciplinares:

Finalmente, a disciplina implica um registro contínuo de conhecimento. Ao mesmo tempo que exerce um poder, produz um saber. O olhar que observa para controlar não é o mesmo que extrai, anota e transfere as informações para os pontos mais altos da hierarquia de poder? (Foucault, 2000, p. XVIII).

É sobre as famílias das classes populares que incide a figura do profissional que observa, controla, extrai informações e as transfere para as instâncias superiores. Assim, os relatos sobre violação de direitos chegam a órgãos fiscalizadores e punitivos. Esse funcionamento está legitimado no trâmite explícito nas ações de acolhimento e de destituição do poder familiar, que devem ser subsidiadas por relatórios minuciosos. Como fazer tais relatórios sem exercer a observação da família, extrair disso informações e enviá-las a outrem? Não tomaria o acompanhamento da família a forma de vigilância e controle?

Vejamos alguns aspectos considerados pelos profissionais nos casos que envolveram afastamento e perda do poder familiar. Um dos motivos alegados para sugerir o acolhimento de crianças que aparece com frequência nos relatos é o do não cumprimento das orientações. Os profissionais relatores referem que, diante de denúncias sobre violação de direitos, conversam com os familiares no intuito de resolver a situação, fazendo orientações e tomando providências. Isso pode ser feito por várias vezes e, quando não se observa mudança, os profissionais podem encaminhar relatórios às instâncias superiores, muitas vezes sugerindo o afastamento da criança. Em determinado caso, um desses relatórios sugeriu o afastamento "diante das inúmeras denúncias que este Conselho Tutelar recebeu e das inexitosas tentativas de um convívio familiar sadio, bem como da negativa da mãe e do avô materno em cumprir nossas deliberações (...)". 
Em outros casos, verificamos situação semelhante, em que a família recebeu atendimentos por algum tempo, mas não alcançou os resultados esperados pelos profissionais.

Desde o ano de 2008, a requerida e sua família vêm recebendo atendimentos do CRAS e de outras entidades. Contudo, mesmo recebendo auxílio e orientação, o comportamento negligente da requerida persiste, de modo que [a mãe] não demonstra mudanças em seu comportamento com relação aos filhos. (Trecho de processo judicial).

Os documentos elaborados por juízes ou promotores de justiça registram que tais profissionais recebem informações dos profissionais da rede de serviços sobre os atendimentos realizados e a persistência da situação considerada violação dos direitos. Pela análise desses documentos, percebemos que o fato de a família não acatar as orientações propostas ou não demonstrar as mudanças desejadas teve bastante influência na decisão pelo afastamento ou mesmo pela perda do poder familiar.

Uma das prerrogativas do ECA é a de que as famílias sejam incluídas em programas sociais, especialmente nos casos de carência material; as crianças e os adolescentes não devem ser afastados de suas famílias por tal motivo. Nas análises sobre as ações dos serviços, vimos que a maioria das famílias foram incluídas nesse tipo de programa: muitas são beneficiárias do Bolsa-Família, recebem cestas de alimentos, leite, roupas e outros benefícios materiais. Também recebem orientações sobre como cuidar dos filhos e sobre o que precisam mudar em sua vida. Mas é preciso apontar a superficialidade que essas ações parecem ter e seu pouco alcance efetivo em relação às famílias. A mudança que os profissionais esperam da família nem sempre é tão simples de ser alcançada, pois envolve aspectos de recursos externos (suporte social e material) e também de recursos internos (subjetivos).

Os profissionais esperam que a família dê respostas de acordo com o que consideram importante para que os filhos permaneçam com ela. Um dos aspectos é o reconhecimento, por parte da família, do erro, da falha cometida em relação aos filhos. Esse processo não é simples, pois envolve fatores culturais, mudança na forma de agir e pensar sobre a relação pais e filhos e sobre sua trajetória e condições de vida. Além disso, os profissionais apontam que a família precisa querer mudar, querer melhorar, abrir-se para as intervenções deles. Para alcançar uma mudança, pontua-se a necessidade de 
compreender como a família concebe suas relações com as crianças e os adolescentes e a de conduzi-la ao reconhecimento daquilo que precisa ser modificado, auxiliando-a para que tenha condições objetivas e subjetivas para tal.

As questões envolvendo o trabalho com as famílias das crianças e dos adolescentes em serviço de acolhimento podem ser consideradas a partir de diferentes olhares. Enquanto algumas famílias apresentam-se fechadas para as intervenções ou não aceitam os encaminhamentos, as orientações, outras se tornam dependentes dos profissionais e dos serviços. Também está compreendido, por alguns profissionais, que estas dificuldades da família em ter autonomia e assumir seu papel são decorrentes de questões sociais como drogadição, ou mesmo da "própria dinâmica familiar" que não permite "dar conta" dos filhos. Mesmo para os profissionais é difícil compreender por que a família se encontra em tal situação, buscando-se a resposta ora nas agruras sociais, ora em questões intrínsecas aos indivíduos ou aos grupos familiares.

Outro tema recorrente é o das informações encaminhadas pelos serviços sobre a negligência praticada pelos pais contra crianças e adolescentes. A negligência pode estar relacionada à falta de cuidados com higiene, alimentação e a uma série de "faltas" cometidas pelos pais, dentre as quais estas: não realizar exames pré-natais, não incentivar a frequência escolar, não atentar para uma possível ocorrência de abuso sexual contra o filho, deixar a criança aos cuidados de vizinhos ou amigos ou deixá-la em casa sozinha.

\footnotetext{
Ao que consta a requerida [mãe] é completamente negligente com a criança, principalmente com relação à higiene $\mathrm{e}$ alimentação, muitas vezes deixando de alimentar e de efetuar a troca de fraldas do filho, não demonstrando interesse em assumir os cuidados e responsabilidades necessários ao desenvolvimento sadio da criança. (Trecho de processo judicial).
}

Algumas questões importantes têm sido consideradas quando se trata da prática de negligência pelos pais ou responsáveis, como a ausência de uma rede de apoio social ou familiar e a factual falta de conhecimento prático de alguns pais sobre o desenvolvimento e as necessidades das crianças e sobre o comportamento infantil. Pesa-se, também, a inabilidade de alguns pais em perceber com precisão os sentimentos e as necessidades dos filhos. Alguns diriam que instintos maternos ou paternos se encarregariam de dar aos pais a orientação para todas essas questões, mas a capacidade de relacionamento humano pressupõe, em grande medida, um 
aprendizado. Pensemos no contexto geral das famílias de nosso estudo: mães adolescentes, com pouco ou nenhum estudo, sem apoio familiar, sem renda, envolvidas com prostituição e drogas. Teriam elas tido oportunidade e condições de aprender sobre as necessidades humanas, desde as mais básicas até as mais complexas? Teriam elas aprendido a alimentar, higienizar e educar os filhos se, em muitos casos, elas próprias não tiveram esses cuidados? As condições de vida dessas mulheres não têm sido consideradas no momento de acusá-las de negligentes e irresponsáveis e não chegam a ter influência na decisão, pois entende-se que tal contexto dificilmente mudará na vida dessas pessoas.

Aproximamo-nos da noção de cuidados parentais e da discussão sobre o que é certo e o que é errado em se tratando da relação pais e filhos. Isso remete aos conceitos de Foucault (2000) sobre a sanção normalizadora como instrumento disciplinar e também aos saberes médicos e psicológicos que ditam como as crianças devem ser cuidadas e educadas de acordo com certos padrões. Tais repertórios de atitudes parentais, quando não cumpridos, são argumentos para a perda do poder familiar.

Referências à família extensa são feitas em vários processos, em alguns casos para demonstrar a impossibilidade de esses membros familiares assumirem as crianças no lugar dos pais. O ECA prevê que as possibilidades de permanência da criança na família de origem incluindo a família extensa sejam esgotadas antes de se proceder ao acolhimento institucional. Muitos profissionais questionam o encaminhamento de crianças e adolescentes para tios, avós ou irmãos sob o argumento de que isso funciona por algum tempo mas as crianças acabam retornando aos Abrigos. Em documento do CONANDA (2008) encontramos que, nos casos em que não é possível o retorno da criança aos pais, deve-se avaliar a possibilidade de reintegrá-la ao convívio com a família extensa e mesmo com pessoas da comunidade que lhe são significativas, e, quando esta for a melhor medida, “(...) deve ser garantida uma aproximação gradativa para a construção da relação afetiva.” (p. 20).

Muitas vezes o interesse de parentes da criança por ela após a institucionalização é visto com desconfiança pelos profissionais, que em sua maioria desencorajam esses parentes a manter contato com a criança ou não favorecem ações de aproximação. Isso acontece sob o argumento da não existência de vínculos ou da falta de interesse desse familiar até o 
momento do afastamento. Assim, tais pessoas são, até mesmo, impedidas de manter contato com a criança, situação que se torna ainda mais evidente quando os interessados não têm grau de parentesco, ainda que sejam pessoas da convivência diária da criança e que lhe sejam significativas.

A percepção dos profissionais sobre a existência de vínculos entre a criança ou $\mathrm{o}$ adolescente e seus familiares tem sido levada em consideração quando se sugere o afastamento ou a destituição do poder familiar. "Considerando-se não existirem fortes vínculos afetivos entre a criança e a requerida, visto Rafael a rejeitar e desejar outra mãe, somos favoráveis à perda do poder familiar. (...) Quanto ao requerido, (...) não possui vínculo com a criança." (Relatório de profissional).

A alegação de que a criança não possui vínculos com algum familiar é feita sem que uma análise mais aprofundada seja empreendida. Parece que, para alguns profissionais, o vínculo entre determinados membros da família prescindiriam da existência de interação entre eles, de modo que não se favorece a construção de tais vínculos. Pais, mães ou outros familiares que não conviveram com as crianças e os adolescentes acolhidos possivelmente não terão vínculos importantes com eles. Para que essa construção aconteça, os profissionais precisam trabalhar pensando em estratégias de formação e fortalecimento dos vínculos, processo que não é simples ou rápido mas pode ser de grande valor para a família e para a criança, que terá a oportunidade de formar laços com membros da família que, no momento de adversidade, a auxiliaram. Apesar disso, os profissionais fazem julgamentos desses familiares, culpando-os por não terem mantido convivência com a criança ou o adolescente antes do afastamento acontecer e invalidando a preocupação que ora apresentam, atrelando-a a outros interesses, como o financeiro. Outra lógica que percebemos na atuação dos profissionais é a de que, se não existem vínculos formados, eles não devem ser incentivados, pois, se não houver sucesso nesse projeto ao longo do tempo, a criança perderá a oportunidade, por exemplo, de ser encaminhada para adoção. Entre a família extensa e a família adotiva, esta tem preferência entre os profissionais, por ser considerada "em condições" e com garantia de cuidar bem da criança em questão, já que passa por um processo de preparo para a adoção, determinado na legislação.

$\mathrm{Na}$ avaliação sobre a relação entre os filhos e seus pais e mães, o olhar sobre a qualidade dos vínculos também existe: 
Considerando que a requerida sequer consegue perceber as necessidades básicas e também afetivas de André, visto considerar positivo que o filho chame de mãe qualquer pessoa do sexo feminino, demonstrando falta de vínculo com ela e ausência de uma única figura que desempenhe adequadamente as funções maternas (...), somos favoráveis à destituição do poder familiar (...) (Trecho de relatório profissional).

O fato de ela não demonstrar preocupação por seu filho chamar outras pessoas de mãe foi considerado negativo pelo profissional e também indicativo de falta de vinculação. Essa noção está permeada de preconceitos e equívocos, bem como de um ideal de figura materna que dita, entre outras coisas, que "mãe é uma só". Para Fonseca (2006), é bastante comum que crianças que circularam entre diferentes famílias reconheçam diversas mães sem que isso interrompa as relações anteriores. "A presença de novas mães não anula a das antigas. Contudo 'a mãe que me criou' nunca é confundida com a que 'me ganhou'." (p. 24).

É comum que as famílias precisem de ajuda para cuidar dos filhos. Em alguns casos que estudamos, porém, isso se transforma em um problema e em argumento para a perda do poder familiar.

\begin{abstract}
Considerando o afirmado por ela própria que indica a necessidade da ajuda de terceiros, os quais não são seus parentes, para que possa ficar com o filho (...) somos favoráveis à destituição do poder familiar, pois entendemos que o encaminhamento de André para uma família substituta na modalidade de adoção significaria ofertar à criança um lar estável, afetivo e protetor. (Trecho de relatório de profissional).
\end{abstract}

Independentemente do trabalho que as mulheres exerçam, não é necessário se debruçar em dados de pesquisa para reconhecer que quase todas necessitam de algum tipo de ajuda para cuidar dos filhos enquanto trabalham. Também observamos, pelo trecho transcrito, que a profissional fez referência ao fato de que as pessoas que cuidavam da criança em questão não tinham grau de parentesco, indicando uma possível preocupação com uma adoção ilegal. Portanto, o fato de precisar de ajuda de outras pessoas para cuidar dos filhos, o de essas pessoas não serem parentes e o de existir apego da criança com seus cuidadores representam algum risco ou perigo e tornam a mãe incompetente no exercício de suas funções.

Fonseca (2008) aborda um ponto importante para nossa análise: a preferência que tem sido dada à família adotiva em detrimento da família de origem das crianças e dos adolescentes, especialmente em detrimento da família 
extensa. Com base em casos em que a convivência não teve êxito e a criança retornou ao serviço de acolhimento, os profissionais consideram o tempo passado com a família um "tempo perdido", pois a criança poderia ter sido adotada. Desconsideram, porém, os inúmeros casos de crianças e adolescentes que estão vivendo bem com seus tios, irmãos, avós, com ou sem conhecimento da justiça. Vejamos o trecho abaixo:

Pelo estudo empreendido restou evidenciado que o investimento na família extensa (...) foi em vão. Já se passou um ano e seis meses e as crianças estão na mesma situação de risco e vulnerabilidade. (...) Assim sendo, somos de parecer que [as crianças] sejam acolhidas imediatamente e que o processo de destituição dos pais seja concluído o mais breve possível. Após, que as crianças sejam encaminhadas para adoção (...) (Trecho de relatório profissional).

Para o profissional autor desse relato, o tempo que as crianças ficaram com a família não foi proveitoso porque elas não permaneceram ali posteriormente. Sob o viés da prevalência da família, proposto pelo ECA, é importante que sejam esgotadas as possibilidades de permanência com a família natural. Para isso, é necessário que sejam feitas tentativas e não há como ter certeza de que a convivência terá êxito ou de que dificuldades não venham acontecer, nem acerca de uma possível impossibilidade de continuidade da convivência. Neste sentido, evidencia-se que, na concepção dos profissionais, o tempo perdido é o tempo para a adoção. O encaminhamento imediato para adoção sem que tentativas de encaminhamento para a família extensa sejam feitas (quando possíveis) não deve se tornar uma prerrogativa. Este argumento da família adotiva como solução para as crianças foi observado com alguma frequência nos documentos: “Somos favoráveis à perda do poder familiar, pois entendemos que $\mathrm{O}$ encaminhamento de André (nome fictício) para uma família substituta na modalidade de adoção significaria ofertar à criança um lar estável, afetivo e protetor." (Relatório profissional).

A família adotiva tem sido referida nos relatórios de profissionais como a possibilidade de tirar a criança da situação de risco e colocá-la em uma família que garantirá estabilidade, afeto e proteção. Assim, para evitar insucessos em relação à família extensa, melhor não fazer tentativas. Os profissionais entendem que o tempo que a criança fica no Serviço de Acolhimento aumenta em função das tentativas que são feitas de reinserção familiar, especialmente na família extensa, 
pois isso leva a reincidências, situação que seria consequência, novamente, da falta de "estrutura" desses familiares para receber a criança e da ineficiência das políticas públicas que auxiliem nessa questão. A busca pela colocação na família extensa é vista por alguns como insistência inócua e que tem como resultado a impossibilidade futura de colocação em adoção.

Outro ponto de vista indicou que é necessário um tempo para que os profissionais consigam avaliar se a família tem condições de receber os filhos de volta. É um tempo de trabalho que não tem determinação prévia e que não garantirá que problemas não voltem a ocorrer após a reinserção.

Então é a questão da reincidência que faz esses questionamentos, que mexe com os profissionais, que aí se pergunta: tá, mas até quando a gente tem que insistir com a família? Porque o tempo passa pra criança, aí a criança fica maior, a dificuldade de adoção também é maior dependendo da idade. (Trecho de entrevista com profissional, 2011).

Alguns profissionais se referem ao tempo que a família precisa para modificar sua situação e ao fato de o tema poder ser tratado sob pontos de vista diferentes: dar tempo à família ou garantir o tempo da criança? Até quando investir na família de origem? Os profissionais apresentam sofrimento diante dessa incerteza e alguns ponderam que a avaliação sobre a possibilidade de uma criança ou um adolescente permanecer com sua família deve ser realizada com maior agilidade e, percebendo-se que a família não apresenta condições, logo se deve proceder à adoção.

\begin{abstract}
A gente visualiza a situação, já sente ali: dá pra investir nessa família? Não tem como? Parte para o judiciário e é melhor que vá pra destituição (...). Porque a gente fica anos, tem casos que vai pro abrigo, volta, que se tivesse ido pra adoção há 10 anos atrás era bem melhor. A rede trabalhou todo esse tempo, se investiu e as crianças chegam à fase da adolescência perdidas, é a palavra, porque a gente tenta, conversa, já não resolve nada, aí eles vão pro ato infracional já. Então, no início é que a gente tem que ter esse olhar. (Trecho de entrevista com profissional, 2011).
\end{abstract}

Vemos ser reforçado o estigma de que a família biológica ou de origem deve ser avaliada sobre as possibilidades de serem feitos "investimentos" sobre ela. Caso contrário, a criança deve ser encaminhada para adoção, como forma de evitar que ela tenha o mesmo destino dos pais e "se perca". Quanto antes a criança for afastada dos seus pais e encaminhada para adoção, melhor, pois se estará garantindo a ela um bom futuro. Existe o sofrimento dos profissionais que 
inicialmente apostaram na reinserção, acreditaram que a criança ficaria bem, e algum tempo depois a veem novamente em situação semelhante: a família sem conseguir atender às expectativas. Quando isso acontece, a ideia de que a adoção rápida é o melhor caminho é reforçada.

Temos falado sobre o peso que pode ter, nos casos de afastamento de crianças e adolescentes de suas famílias e de ações de destituição, a história pregressa da família como justificativa para a perda do poder familiar. Famílias com história de violência doméstica ou sexual, entrega de filhos para adoção, perda do poder familiar sobre filhos, dentre outras situações, ficam reféns de suas próprias histórias e são consideradas inaptas para o cuidado de crianças pelo resto de suas vidas.

(...) a tia, por sua vez, apesar de aparentemente cuidar bem do sobrinho, detém um histórico de perda do poder familiar em relação a dois filhos, o que vem a gerar insegurança no tocante ao futuro de Eduardo [nome fictício], pois não há garantias de que oferecerá à criança a proteção e os cuidados que o menino necessita. (Trecho do processo judicial).

São estabelecidas relações de causa e efeito entre a história da família e a certeza de perpetuação dessa história. A família que teve filhos afastados de sua convivência em tempos anteriores é considerada inapta para cuidar de crianças em momentos posteriores, a mãe que entregou um filho para adoção também não é vista como mãe exemplar. Se os filhos anteriores tiveram problemas, os atuais e futuros também terão. Se a família não conseguiu cuidar bem de um dos filhos, não conseguirá cuidar bem de outros que tenha ou que vier a ter.

Scheinvar (2002) analisa que os fenômenos sociais que se apresentam em questões judiciais envolvendo crianças e adolescentes são vistos sob a ótica dominante na sociedade e esta se torna o critério da normalidade. Outras formas de organização, que sejam divergentes, são consideradas irregulares. Neste sentido é que mães que deixam os filhos aos cuidados de outras pessoas, mães que trabalham na prostituição, mães sem companheiro fixo e mães sob outras situações relatadas nos casos estudados são consideradas inaptas para a função de cuidar de seus filhos.

\footnotetext{
A prática política desqualifica as formas de vida produzidas em contextos sociais datados e reconhecidos como cenários de exclusão social, individualizando casos que se repetem massivamente, eximindo-se o poder público da responsabilidade maior de ter determinado não só as condições de
} 
pobreza, mas também as alternativas a ela.

(Scheinvar, 2002, p. 85).

Assim como Ayres (2002), também observamos que alguns profissionais demonstram reconhecer as condições de pobreza das famílias. Mas indubitavelmente a ênfase dos discursos e opiniões não está centrada na reflexão sobre essas situações, e sim na culpabilização das famílias e no julgamento de suas "escolhas" pela prostituição, pelas drogas, pela negligência, pela pobreza.

As informações constantes nos autos com relação a sua pessoa [mãe] dão conta de que é usuária costumaz de entorpecentes (crack) e que sua renda provém de seu labor como prostituta. Sobre sua situação econômica e social, temos que a requerida é paupérrima, com baixo nível de escolaridade, não possui renda ou residência fixa. (...) O Estado não pode ser conivente com a desídia, o descaso e o abandono moral e material dos pais em relação aos filhos, pois os direitos dos incapazes suplantam os daqueles que são irresponsáveis diante da maternidade e paternidade. (Trecho de processo judicial).

As formas alternativas de vida encontradas pela mãe ou as condições "paupérrimas" de vida das mães desse estudo referido podem ser consideradas "escolhas"? Essas condições de vida têm sido tratadas como fracassos individuais (Ayres, Cardoso \& Pereira, 2009; Scheinvar, 2002).

Uma análise geral das posições e concepções dos profissionais sobre as famílias, especialmente nos casos das que tiveram os filhos afastados de sua convivência ou das que foram destituídas do poder familiar, conduz à confirmação de compreensões de autores como Sales, Matos e Leal (2009). Para eles, as intervenções do Estado sobre as famílias, embora busquem defender crianças e adolescentes da violação de seus direitos, acabam impondo à família normas socialmente definidas como as corretas e exercendo sobre ela estratégias de controle. A noção que subjaz aos discursos dos profissionais - e que foi construída na história da relação entre Estado e família é a de que as famílias devem ser capazes de cuidar e proteger seus membros independentemente de suas condições de vida. Isso promoveu a distinção que está tão presente acerca da família capaz e da incapaz, calcada em estereótipos como o do ideal de mãe.

Nas práticas cotidianas de alguns profissionais, podemos localizar, especialmente quando se referem ao "refletir" com a família, "orientar" a família, o uso das tecnologias do eu abordadas por Foucault (1993): confissão e 
exame de consciência. A família que está perante os profissionais precisa admitir e assumir suas falhas; enfim, confessar a sua vida. Portanto, a confissão coloca em funcionamento "um conjunto de relações de poder entre aqueles que afirmaram ser capazes de extrair a verdade destas confissões através da posse de chaves de interpretação" (Dreyfus \& Rabinow, 1995, p. 192).

Assim, as famílias que têm os filhos afastados de sua convivência passam a ter a vida esquadrinhada, na busca por falhas que tenham cometido e para encontrar nelas o conjunto de fatores de risco que indiquem e comprovem sua incapacidade de cuidar de crianças. Os profissionais identificam essa família incapaz, capturam-na, cercam-na com orientações, advertências, vigilâncias, condicionalidades. Ouvem essas pessoas em seus locais de trabalho e buscam os tropeços e as confissões que poderão confirmar sua condição de incapaz.

Além da confissão, mães, pais e outros familiares devem fazer exame de consciência, ou seja, devem dar-se conta de suas atitudes erradas, suas falhas e adaptar sua forma de viver aos valores da sociedade. Percebemos, assim, que se espera, com a ajuda dos especialistas, que as famílias possam falar a verdade e também manter vigilância sobre si mesmas.

Desse modo, as ações de afastamento de crianças de suas famílias parecem constituir-se em reatualizações de práticas menoristas, pois pretendem prevenir situações de risco, romper ciclos de violência, impedir que as crianças passem a viver nas mesmas condições de seus pais. A ênfase na aliança das medidas de rompimento com a família de origem e encaminhamento para adoção parece funcionar como uma estratégia de controle (da pobreza).

$\mathrm{Na}$ busca por este objetivo de "salvar" as crianças de um futuro nefasto na convivência com suas famílias de origem, os profissionais buscam cruzar "diversos fatores assinalados como de risco, que permitam calcular a probabilidade do aparecimento de comportamentos indesejados" (Hillesheim \& Cruz, 2008, p. 195). Encontramos esse cruzamento de fatores (drogadição, prostituição, falta de rede de apoio, doenças na família, histórico "negativo", entre outros) em vários dos casos estudados nesta pesquisa.

\section{Considerações Finais}

Os profissionais participantes da pesquisa apresentam a concepção de que as 
famílias das crianças e dos adolescentes que foram afastados da convivência se mostram incapazes na tarefa de cuidar dos filhos, e isso em consequência de escolhas individuais que tenham feito por modos de vida que não condizem com o esperado socialmente para maternidade/paternidade. Estão presentes em suas práticas discursivas e não discursivas estigmas e preconceitos depositados sobre membros da família, muitas vezes descolados de qualquer reflexão ou consideração acerca dos condicionantes históricos, sociais e culturais que os envolvem.

As crianças e os adolescentes são avaliados também em sua capacidade de vinculação futura a uma família adotiva, fator levado em consideração inclusive para sugerir ações de destituição familiar. Crianças com baixa idade e comportamento fácil parecem ser mais frequentemente objeto de discursos de desqualificação da família de origem e de impossibilidade de estas permanecerem com os filhos, de maneira que eles venham a ser encaminhados para uma família que lhes ofereça o que a biológica não consegue: a garantia de um futuro seguro. A atuação tem se dado com base em normas socialmente estabelecidas consideradas modelos únicos de conduta a serem acatados pelas famílias, que precisam adequar-se e cumprir os ditames dos profissionais sob pena de terem os filhos afastados de sua convivência.

$\mathrm{Na}$ opinião dos profissionais, crianças e adolescentes precisam ser afastados de suas famílias porque estas não modificam suas vidas conforme as orientações recomendadas pelos serviços de atendimento. Observamos que, na maioria dos casos, o afastamento da família ocorreu sem que trabalhos anteriores fossem realizados com a família (exceto orientações, advertências e repasse de alguns benefícios que vimos não alcançarem os resultados esperados). Alguns dos participantes identificam que a ineficácia das políticas públicas está no cerne na questão, mas ainda assim seus relatórios profissionais prescindem de análises que considerem esse contexto, acabam depositando sobre a família, unicamente, a responsabilidade pela situação vivida e detectando risco às crianças e aos adolescentes de seu núcleo. Dentre os motivos expressos nos documentos em relação ao afastamento, a negligência figura em primeiro lugar; apontamos, pois, a estreita relação que a negligência tem com a condição precária de vida das pessoas nos casos estudados. Os motivos referidos para justificar o afastamento da família estão relacionados a um contexto de pobreza e falta de acesso à 
cidadania, bem como a problemáticas sociais abrangentes como o tráfico e uso de drogas, a criminalidade, a prática da violência, a precariedade de vida.

Foi possível compreender como os discursos de "verdades" sobre as famílias e de normatização de suas vidas estão presentes, bem como o fundo de punição de seus atos com a retirada dos filhos. Esses discursos se vinculam a uma rede discursiva, na qual se conectam uma multiplicidade de enunciados, em um campo complexo de discursos.

Assim, tanto as políticas públicas que visam ao fortalecimento e à manutenção de vínculos familiares quanto as que visam à ação dos profissionais envolvidos no sistema de garantias de direitos da criança e do adolescente, que afastam as crianças e os adolescentes das famílias consideradas inaptas, fortalecem a instituição familiar como foco das atenções das ações públicas. Nos dois casos, trata-se de manter a concepção abstrata da família como protetora de riscos sociais para seus membros, o que não tem contribuído para a organização das famílias em contexto de pobreza, nem para o acesso destas à cidadania.

\section{Referências}

Ayres, L. S. M., Cardoso, A. P., \& Pereira, L. C. (2009). O abrigamento e as redes de proteção para a infância e a juventude. Fractal: Revista de Psicologia, 2 (1), 125-136.

Conanda, Conselho Nacional de Assistência Social (2008). Orientações técnicas para os serviços de acolhimento para crianças e adolescentes. Brasília: CONANDA.

Dreyfus, H., \& Rabinow P. (1995). Michael Foucault: uma trajetória filosófica. Rio de Janeiro: Forense Universitária.

Fonseca, C. (2006). Da circulação de crianças à adoção internacional: questões de pertencimento e posse. Dossiê: repensando a infância. Cadernos Pagu, 26, 11-43.

Foucault, M. (1993). História da sexualidade 1: a vontade de saber. 11. ed. Rio de Janeiro: Graal.

Foucault, M. (1995). A arqueologia do saber. Rio de Janeiro: Forense Universitária.

Foucault, M. (2000). Microfísica do poder. 15. ed. Rio de Janeiro: Graal.

Hillesheim, B., \& Cruz, L. R. (2008). Risco, vulnerabilidade e infância: algumas aproximações. Psicologia e sociedade, 20 (2), 192-199. 
Nascimento, M. L., Cunha, F. L., \& Vicente, L. M. D. (2008). A desqualificação da família pobre como prática de criminalização da pobreza. Revista Psicologia Política, 14 (7), Rio de Janeiro.

Sales, M. A., Matos, M. C., \& Leal, M. C. (2006). Política social, família e juventude: uma questão de direitos. São Paulo: Cortez.

Scheinvar, E. (2002). Idade e proteção: fundamentos legais para a criminalização da criança, do adolescente e da família (pobres). Em Nascimento, M. L. (Org.). Pivetes: a produção de infâncias desiguais. Rio de Janeiro: Oficina do Autor.

\section{Mara Fernanda Córdova: Mestranda em \\ Políticas Sociais e Dinâmicas Regionais da Universidade Comunitária da Região de Chapecó, Psicóloga pela Unochapecó em 2003, atua como Psicóloga do Tribunal de Justiça de Santa Catarina. \\ E-mail: marafernanda@unochapeco.edu.br}

Irme Salete Bonamigo: Doutora em Psicologia Social pela Universidade do Estado do Rio de Janeiro (UERJ), docente do Programa de Pós-Graduação Mestrado em Políticas Sociais e Dinâmicas Regionais e do Curso de Psicologia da
Universidade Comunitária da Região de Chapecó (Unochapecó).

E-mail: bonamigo@ unochapeco.edu.br 